Article

\title{
Real-Time Monitoring of Biotinylated Molecules Detection Dynamics in Nanoporous Anodic Alumina for Bio-Sensing
}

\author{
Laura Pol ${ }^{\circledR}$, Chris Eckstein, Laura K. Acosta, Elisabet Xifré-Pérez, Josep Ferré-Borrull * \\ and Lluis F. Marsal *(D) \\ Departament d'Enginyeria Electrònica, Elèctrica i Automàtica, ETSE, Universitat Rovira i Virgili, \\ Avda. Països Catalans 26, 43007 Tarragona, Spain; laura.pol@urv.cat (L.P.); chris.eckstein@urv.cat (C.E.); \\ laurakaren.acosta@urv.cat (L.K.A.); elisabet.xifre@urv.cat (E.X.-P.) \\ * Correspondence: josep.ferre@urv.cat (J.F.-B.); lluis.marsal@urv.cat (L.F.M.); Tel.: +34-977-55-96-25 (L.F.M.)
}

Received: 22 February 2019; Accepted: 19 March 2019; Published: 23 March 2019

check for updates

\begin{abstract}
The chemical modification, or functionalization, of the surfaces of nanomaterials is a key step to achieve biosensors with the best sensitivity and selectivity. The surface modification of biosensors usually comprises several modification steps that have to be optimized. Real-time monitoring of all the reactions taking place during such modification steps can be a highly helpful tool for optimization. In this work, we propose nanoporous anodic alumina (NAA) functionalized with the streptavidin-biotin complex as a platform towards label-free biosensors. Using reflective interferometric spectroscopy (RIfS), the streptavidin-biotin complex formation, using biotinylated thrombin as a molecule model, was monitored in real-time. The study compared the performance of different NAA pore sizes in order to achieve the highest response. Furthermore, the optimal streptavidin concentration that enabled the efficient detection of the biotinylated thrombin attachment was estimated. Finally, the ability of the NAA-RIfS system to quantify the concentration of biotinylated thrombin was evaluated. This study provides an optimized characterization method to monitor the chemical reactions that take place during the biotinylated molecules attachment within the NAA pores.
\end{abstract}

Keywords: nanoporous anodic alumina; streptavidin; biotin; RIfS; biosensing

\section{Introduction}

In the last few decades, many different classes of biosensors for biomedical applications have received great attention [1-3]. The principles of a biosensor consist of a bio-receptor (antibodies, aptamers), a transducer, and a signal processor. In practice, a transitional chemical interface is commonly introduced between the transducer and bio-receptor to promote the access of the target to the bioreceptor. Such a transitional chemical interface comprises chemical molecules with convenient functional groups, whose purpose is to facilitate the attachment of the bioreceptor in the most efficient manner.

Optical biosensors are based on the interaction of light with a biorecognition element. There are two principal categories of optical biosensors: label-based and label-free sensors. Label-based sensors rely on using labeled molecules that produce a colorimetric, fluorescent, or luminescent signal whereas in label-free sensors the signal is directly generated by the interaction of the biomolecules with the surface $[4,5]$. Labeling assays only provide endpoint read outs, and do not allow continuous monitoring. Furthermore, labeling assays need exhaustive washing processes, and the labeling molecules can interfere with the interaction of key molecules during the bioreception process because they can block access to the binding sites. 
On the other hand, in optical label-free sensors, it is possible to monitor continuous binding events in real-time. Several label-free biosensor techniques are reported in the literature. For instance, surface plasmon resonance (SPR) [6,7], localized surface plasmon resonance (LSPR) [8-10], ellipsometry [11], surface-enhanced Raman spectroscopy (SERS) [12]. In particular, the reflectance interference spectroscopy (RIfS) technique has demonstrated its capability to monitor biomolecule interactions in real-time with simple and cost-effective procedure in porous silicon and nanoporous anodic alumina (NAA) [13] with proteins [14,15], antibodies [16,17], aptamers [18], or cells [19].

Nanoporous anodic alumina has been used as a promising biosensor platform in the last few years [20,21]. NAA is a material with straight pores growing perpendicular to the surface with a cost-effective fabrication process that provides a well-defined and controllable geometry [22]. Furthermore, NAA can be easily modified chemically and provides a biocompatible platform with high surface-to-volume ratio with chemical resistance, thermal stability, and hardness [23]. The surface chemistry of NAA permits the introduction of useful functional groups (e.g., carboxyl, amin) by means of self-assembly silanization with aminopropyl-triethoxy silane (APTES) [24], mercaptopropyl-triethoxy silane [25], 3-isocyanatopropyl triethoxy silane (ICN) [26], polyethylene glycol-silane (PEG-silane) [27], and several other silanes. Moreover, NAA possesses unique optical properties, such as characteristic reflectance spectra governed by Fabry-Perot interferences, that exploit NAA as a platform to study the chemical interactions in biosensors using RIfS [28,29].

On account of its suitable properties, streptavidin is a protein widely used in the transitional chemical interface to facilitate the access of the bioreceptor to the target [25]. It is reported that the avidin-biotin interaction is one of the strongest non-covalent interactions in nature. Streptavidin is an analog of avidin that is extracted from Streptomyces avidinii with a molecular weight of $58 \mathrm{kDa}$ [30]. Streptavidin is a tetrameric protein able to bind with four biotins with a dissociation constant of $10^{-15} \mathrm{M}$ [31]. It is reported that streptavidin is a protein with a long half-life (around 50 days) [32] and is one of the most thermally stable proteins. Furthermore, the streptavidin-biotin complex can persist stably for $35 \mathrm{~h} \mathrm{[33].} \mathrm{Biotin} \mathrm{is} \mathrm{also} \mathrm{a} \mathrm{very} \mathrm{stable} \mathrm{molecule} \mathrm{and} \mathrm{easy} \mathrm{to} \mathrm{bind} \mathrm{covalently} \mathrm{to} \mathrm{most} \mathrm{of} \mathrm{the}$ biomolecules, and a very wide range of commercial biotinylated molecules for biosensor applications can be found. Several studies report positive results on the streptavidin-biotin system in NAA to check covalent attachment [34] or to immobilize cell proteins [19]. Thrombin is a plasmatic protein involved in blood coagulation processes with a well-known structure and properties [35]. Thrombin has been studied as a target model in several biosensor approaches such as electrochemical [36,37], colorimetric [38], and fluorescence [39,40] biosensors.

Because of the properties described above, NAA with streptavidin in the transitional chemical interface can be a very versatile and stable platform that permits the achievement of specific and sensitive biosensors. In this work, we study the transitional chemical interface formation using RIfS in real-time, as well as the further attachment of a biotinylated model molecule, which in this case is thrombin. With this, it is possible to obtain information about the dynamics of the binding of streptavidin to the silanized surface of NAA. Furthermore, we show that RIfS permits to monitor in real-time and to quantify the attachment process of the biotinylated molecule to the transitional chemical interface. In addition, this work also permits to study the sensitivity of an NAA platform to the detection of biotinylated thrombin.

\section{Materials and Methods}

\subsection{Materials}

Aluminum foils of $99.999 \%$ of purity and $0.5 \mathrm{~mm}$ of thickness were purchased from Goodfellow Ltd. (Cambridge, UK). Oxalic acid $\left(\mathrm{H}_{2} \mathrm{C}_{2} \mathrm{O}_{4}\right)$, phosphoric acid $\left(\mathrm{H}_{3} \mathrm{PO}_{4}\right)$, perchloric acid $\left(\mathrm{HClO}_{4}\right)$, chromium oxide $\left(\mathrm{CrO}_{2}\right)$, copper chloride $\left(\mathrm{CuCl}_{2}\right)$, ethanol $\left(\mathrm{C}_{2} \mathrm{H}_{5} \mathrm{OH}\right)$, acetone $\left(\left(\mathrm{CH}_{3}\right)_{2} \mathrm{CO}\right), 2-(\mathrm{N}-M o r p h o l i n o) e t h a n e s u l f o n i c ~ a c i d ~(M E S)$, phosphate buffered saline (PBS), bovine serum albumin (BSA), phosphate buffered saline with Tween ${ }^{\mathrm{TM}} 20$ (PBS-T), streptavidin, 
N-Hydroxysuccinimide (NHS), N-(3-Dimethylaminopropyl)-N'ethylcarbodiimide hydrochloride (EDC), (3-Aminopropyl)triethoxysilane (APTES), and thrombin were purchased from Merck KGaA (Darmstadt, Germany)Biotinylated thrombin was purchased from Thermo Fisher Scientific (Madrid, Spain). Double-deionized (DI) water (18.6 M $\Omega$, PURELAB Option-Q) was used for all solutions.

\subsection{NAA Fabrication}

NAA samples were fabricated by the well-known two-step anodization method [41] with $0.3 \mathrm{M}$ of oxalic acid at $40 \mathrm{~V}$ and $5{ }^{\circ} \mathrm{C}$ following the protocol described in the literature [42]. The first step was carried out during $20 \mathrm{~h}$; this first formed alumina layer was removed during $3 \mathrm{~h}$ in an etching solution of $\mathrm{H}_{3} \mathrm{PO}_{4} 6 \% \mathrm{wt}$. and $\mathrm{H}_{2} \mathrm{CrO}_{7} 1.8 \% \mathrm{wt}$. at $70{ }^{\circ} \mathrm{C}$. The second step was carried out until a total charge of $Q=20 \mathrm{C}$ per sample was used in the anodization. The area of one sample was $1.7 \mathrm{~cm}^{2}$. In this way, samples with an NAA layer with $5 \mu \mathrm{m}$ depth pores and $30 \mathrm{~nm}$ pore diameter were obtained. The pore diameter was then adjusted to $50 \mathrm{~nm}$ and $60 \mathrm{~nm}$ by immersion on NAA in $\mathrm{H}_{3} \mathrm{PO}_{4}$ at $35^{\circ} \mathrm{C}$ during 10 and $20 \mathrm{~min}$ respectively. These values of pore diameter are the lowest and highest that give a measurable signal in the RIfS procedure. Pore radii smaller than $50 \mathrm{~nm}$ hinders the diffusion of the molecules into the pores, while pore radii bigger than $60 \mathrm{~nm}$ result in a layer too porous to create the light interferences necessary for the RIfS technique. Figure S1 in the supplementary information shows two top-view SEM pictures of samples with $50 \mathrm{~nm}$ and $60 \mathrm{~nm}$ pore diameter (a and b), respectively, and a cross-section image of the sample with a pore diameter of $50 \mathrm{~nm}$ (c). The images show that pore sizes have a small dispersion in diameter and that pores grow uniformly along its length.

\subsection{Sample Preparation}

Before the real-time interferometric measurements, the samples were chemically pretreated by immobilization of APTES, as shown in Figure 1, in the NAA surface. Firstly, the NAA was hydroxylated by immersion in boiling hydrogen peroxide $\left(\mathrm{H}_{2} \mathrm{O}_{2}\right)$ as reported in previous works [34] for $1 \mathrm{~h}$ with continuous stirring followed by a washing step with ethanol and dried under a nitrogen flux. Then NAA was incubated for $1 \mathrm{~h}$ in a solution with $15 \mathrm{~mL}$ of anhydrous toluene and $1.5 \mathrm{~mL}$ of APTES with continuous stirring under nitrogen flux. Next, the NAA were sonicated in a toluene bath for $5 \mathrm{~min}$ to remove remaining APTES. Finally, the NAA with APTES was washed again with ethanol, dried under nitrogen flux, and placed in the oven at $110{ }^{\circ} \mathrm{C}$ overnight to promote silane cross-linking. Just before the streptavidin-biotininylated thrombin binding experiments, a thin film of $10 \mathrm{~nm}$ gold was deposited onto the NAA by sputtering.

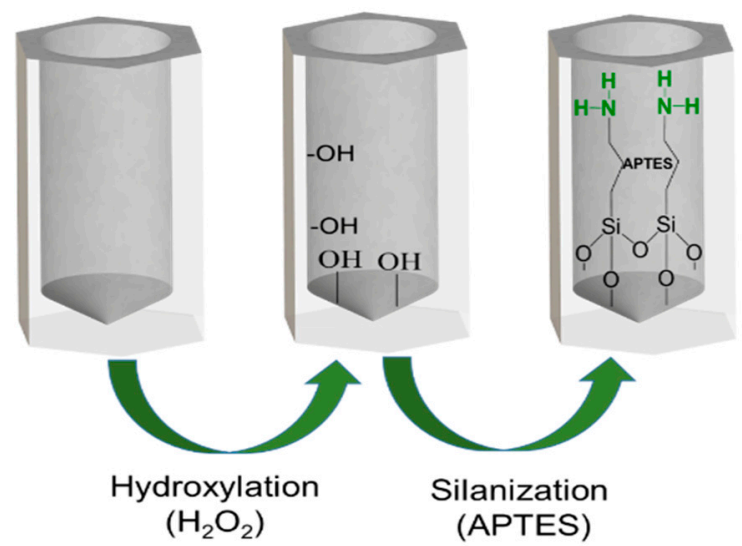

Figure 1. Schematics of the steps for the immobilization of APTES in NAA.

\subsection{Reflectometric Interference Spectroscopy System (RIfS)}

RIfS is a technique based on the measurement of the changes in the effective refractive index of NAA thin films when molecules attach to the inner pore surface. The basics of RIfS detection in flow 
cell are illustrated in Figure 2. NAA was placed in a transparent flow cell system which permitted the flow of different solutions with a rate of $500 \mu \mathrm{L} / \mathrm{min}$ and its diffusion into the pores. The total volume of the solutions (streptavidin and biotinylated thrombin) was $1 \mathrm{~mL}$ and they were recirculated in the flow cell during all the infiltration steps. Previous experiments with glucose solutions demonstrated that molecules diffuse fast and completely along the pores [29]. After diffusion, molecules can attach to the inner pore surface contributing to the change in effective refractive index. Simultaneously, white light is directed to the NAA surface and the reflected light was collected by a spectrometer which registered an interferometric reflectance spectrum. Interferences arose from the optical path difference between the two beams reflected at the top and bottom interfaces of the NAA film as in a Fabry-Perot interferometer. Since the light reflected at the bottom traveled across the pore, the optical path difference was directly proportional to the effective refractive index of the NAA layer, constituted by the oxide, the medium filling the pores and the molecular layers deposited on the inner pore surfaces. The interferometric reflectance spectrum showed oscillations that were analyzed by a Fourier transform procedure that allowed us to estimate the optical path thickness which could then be related to the effective optical thickness (EOT, defined as the physical thickness times the effective refractive index) of the NAA layer. The spectrometer measured one spectrum every $10 \mathrm{~s}$ and the Fourier transform was calculated by the same computer controlling the spectrometer using a custom-made MATLAB script. This allowed us to observe the changes in the EOT in real-time.

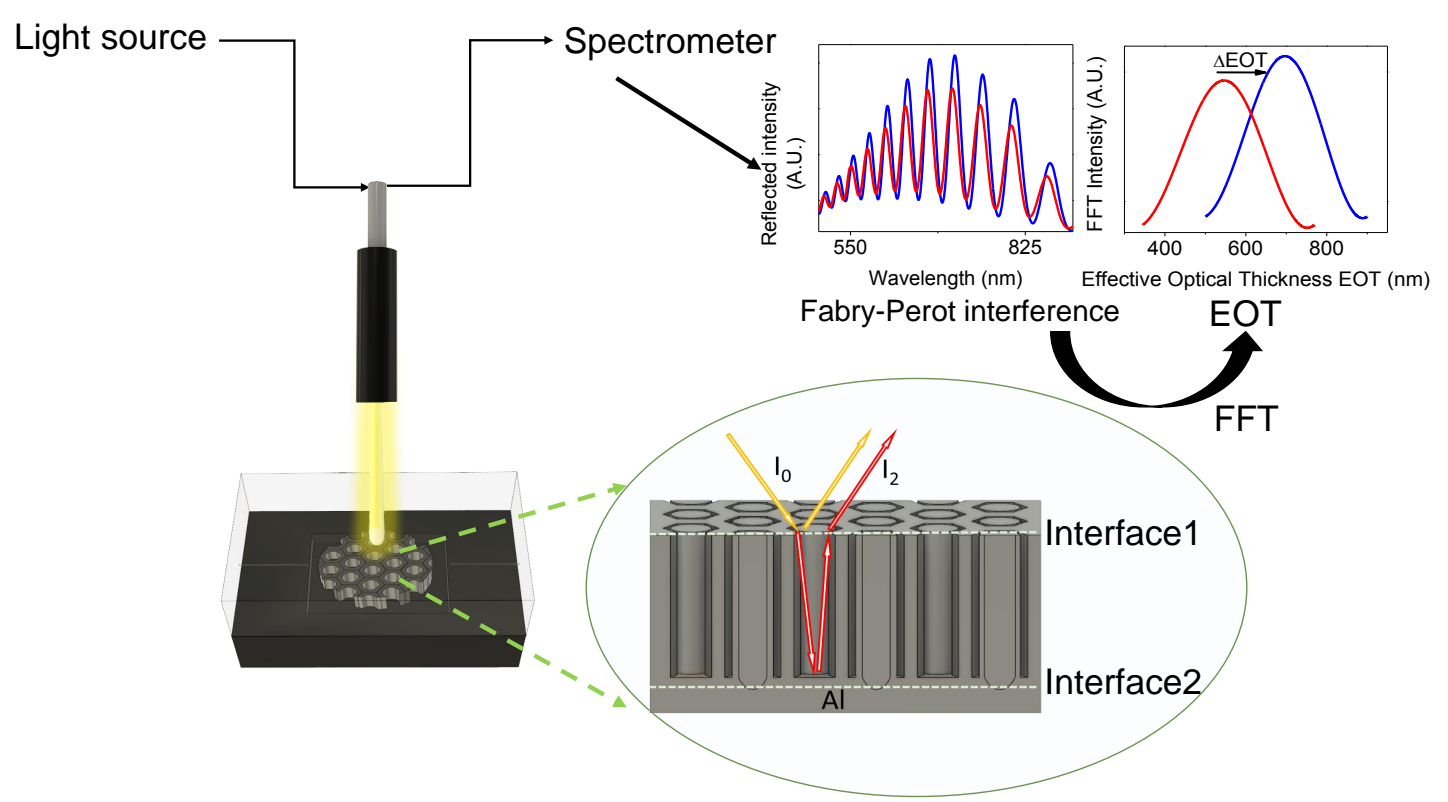

Figure 2. Schematic of the reflectance interferometric spectroscopy and flow cell system.

\subsection{Real-Time Monitoring of Biotinylated Thrombin Attachment to Streptavidin into NAA Pores}

In each of the binding experiments, one pretreated NAA sample with APTES was placed in the flow cell system to monitor the biotinylated thrombin attachment in NAA in real-time, as shown in Figure 3. Before each experiment, a preparation step was applied consisting of flowing PBS until a steady value of EOT registered. Simultaneously to this preparation step, streptavidin was incubated for 20 min with EDC and NHS in a proportion of 1:10:25, respectively, to activate the carboxyl groups of streptavidin.

The first step in the experiment was the injection of this activated streptavidin solution in the flow cell. The instant at which the activated streptavidin solution is injected in the flow cell is defined as the initial time $(t=0 \mathrm{~s})$ and the EOT at that instant is taken as the reference EOT, EOT $\mathrm{E}_{0}$ In this first step, the free amino group of APTES $\left(-\mathrm{NH}_{3}\right)$ formed a peptide bond with the carboxyl group of 
streptavidin $(-\mathrm{COOH})$. This first step was applied until a stable EOT value was observed. After this, PBS was flowed to remove any non-specifically attached streptavidin molecules.

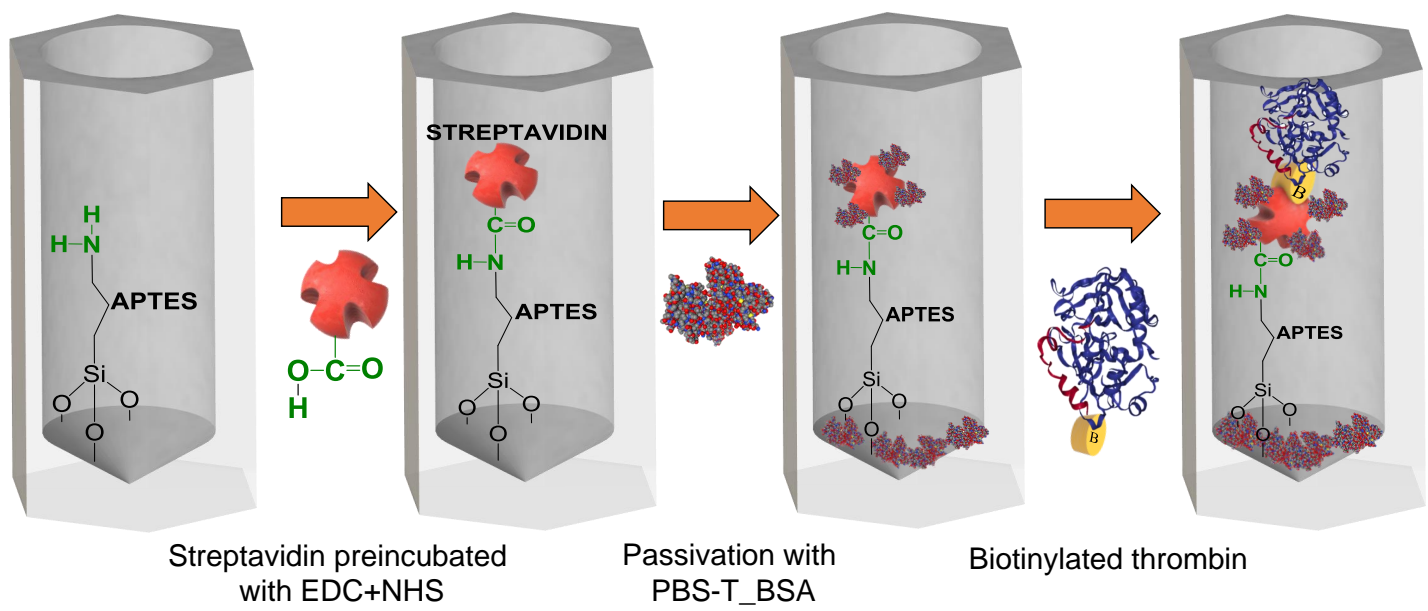

Figure 3. Schematics of the different NAA modification steps in the real-time monitoring of biotinylated thrombin attachment experiments.

The second step consisted of the injection of 3\% BSA with 0.05\% Tween 20, pH 7.4 (PBS-T_BSA) to block the remaining sites on the NAA pore surface and the free carboxyl groups of streptavidin that did not attach to the amino groups of APTES, which could lead to non-specific bindings. To end this second step, a flow of PBS was introduced to wash unbound remaining molecules.

The third and final step in the experiments was to flow the biotinylated thrombin solution. As in the previous steps, a wash with PBS was introduced to finish, and the variation in EOT was registered. The total EOT variation in this experiment was designated as $\Delta \mathrm{EOT}$.

\section{Results and Discussion}

\subsection{Study of the Influence of the Pore Diameter in the Detection of the Biotinylated Thrombin}

The first goal of this work was to evaluate the ability of RIfS to detect the binding of a biotinylated molecule to streptavidin that is grafted on the pore walls of NAA and the influence of the pore size in the event of detection. Figure 4a shows a characteristic example of the evolution of EOT along the streptavidin-biotinylated thrombin attachment experiment. The data correspond to an NAA with $60 \mathrm{~nm}$ diameter pores and to a concentration of streptavidin in the first step of $50 \mu \mathrm{g} / \mathrm{mL}$. The dashed lines indicate the starting time for each step in the experiment. First, an increase in EOT is observed as streptavidin is attached. Such an increase shows three different stages: the first one with a bigger slope, followed by a smaller rate of growth, and reaching a steady value at the end. When a steady EOT value is reached, PBS is flowed to remove any non-specifically attached streptavidin molecules, resulting in a sudden decrease in EOT of $2.4 \mathrm{~nm}$, which corresponds to a $4.4 \%$ decrease of the value obtained at the end of the streptavidin step.

The next step consists of passivation with 3\% bovine serum albumin in the PBS-T which results in a fast increase of $10 \mathrm{~nm}$ EOT followed by a steady value for $192 \mathrm{~s}$. After this, again PBS is flowed to clean any non-attached BSA with a reduction of EOT as a consequence. It has to be noted that if the BSA passivation step and the subsequent PBS cleaning are considered as a whole, the EOT reaches a value greater than that achieved by the previous streptavidin step.

Next, biotinylated thrombin at a concentration of $20 \mu \mathrm{g} / \mathrm{mL}$ is flowed through the cell for $1285 \mathrm{~s}$. A slow and steady increase in EOT is observed with a final value of $3.6 \mathrm{~nm}$ above the initial one. Finally, after this step, a flow of PBS is introduced which does not produce any noticeable change in the EOT.

The increase in EOT observed at the streptavidin step, and the small decrease with the subsequent PBS cleaning step are consistent with the attachment of the streptavidin molecule to the APTES on the 
NAA pore surface and with the removal of the non-bound molecules with the PBS flow. The increase and stable value of the signal at the BSA passivation stage can be explained by the fact that BSA is occupying the free spaces between the APTES molecules on the NAA pore surfaces. The higher value of EOT after such a step indicates that a certain amount of BSA remains attached to the pore walls, actually passivating the NAA surface and the carboxyl groups in the streptavidin. Finally, the increase in EOT in the biotinylated thrombin binding step certifies the ability of the RIfS method to detect such a binding event.

The graphs in Figure $4 b, c$ show the evolution of EOT corresponding to the last step in the experiment (biotinylated thrombin binding) for two different NAA with $50 \mathrm{~nm}$ diameter pores, while Figure $4 \mathrm{~d}$,e correspond to NAA with $60 \mathrm{~nm}$ diameter pores. The plots include a best-fit curve with exponential dependence:

$$
E O T-E O T_{0, t h}=A \cdot\left(1-e^{-\frac{t-t_{0, t h}}{B}}\right)
$$

where $t_{0, \text { th }}$ corresponds to the time of introduction of the biotinylated thrombin solution, $\mathrm{EOT}_{0, \text { th }}$ corresponds to the EOT value at that instant, $\mathrm{A}$ and $\mathrm{B}$ are the adjusted parameters of amplitude and reaction time. With the best fit, the values of $A$ and $B$ can be used to obtain a robust estimate of the total variation of EOT in this step, designated as $\triangle \mathrm{EOT}$.

In all cases, a steady increase of EOT with time is observed and the increase is correlated with the pore diameter: the estimated average increase for $50 \mathrm{~nm}$ diameter is $3 \mathrm{~nm}$, while the average increase for $60 \mathrm{~nm}$ diameter is $11 \mathrm{~nm}$. The complete evolution of the EOT with time for such experiments is shown in Figure S1 of the supplementary material. This result indicates that a bigger pore diameter improves the detectability of the binding of biotinylated molecules onto streptavidin-functionalized NAA.

\subsection{Influence of the Streptavidin Concentration in the First Step}

It has been noticed that the change of EOT over time in the streptavidin binding step shows two different stages, an initial one at a high increase rate, followed by another stage at a smaller increase rate. In order to understand the reasons for such behavior, a study was conducted to test the coverage of the NAA pores with streptavidin, for different streptavidin concentrations. The study was carried out for $60 \mathrm{~nm}$ pore diameter NAA and for decreasing streptavidin concentrations from $50 \mu \mathrm{g} / \mathrm{mL}$ and down to $0.5 \mu \mathrm{g} / \mathrm{mL}$. Figure 5 shows the results of this study, where graphs a) to e) plot the change in EOT for the streptavidin binding step at concentrations of $50 \mu \mathrm{g} / \mathrm{mL}, 5 \mu \mathrm{g} / \mathrm{mL}, 3 \mu \mathrm{g} / \mathrm{mL}, 1 \mu \mathrm{g} / \mathrm{mL}$, and $0.5 \mu \mathrm{g} / \mathrm{mL}$, respectively.

It was observed that the flow of the streptavidin solution resulted in a clear increase in EOT for all studied concentrations. The graphs a) to e) can be classified into two main groups: for the 50, 5 and $3 \mu \mathrm{g} / \mathrm{mL}$ concentrations, two different stages in the EOT variation can be identified; a first one in which a fast increase in EOT is observed until an inflection point is reached in a short time $(60 \mathrm{~s}$ for $50 \mu \mathrm{g} / \mathrm{mL}, 157 \mathrm{~s}$ for $5 \mu \mathrm{g} / \mathrm{mL}$ and $408 \mathrm{~s}$ for $3 \mu \mathrm{g} / \mathrm{mL}$ ), followed by a second stage with a slower increase in rate. This second stage reaches a steady EOT value after a given time, at which PBS is introduced in the flow cell to remove all the non-bound molecules (the start of this washing step is indicated by the vertical dashed lines in the graphs a) to e) of Figure 5). However, for the $1 \mu \mathrm{g} / \mathrm{mL}$ and $0.5 \mu \mathrm{g} / \mathrm{mL}$ concentrations, only one stage is recognized: a fast increase in EOT which reaches a stable value in a short time that is not followed by a second increase.

The time at which a stable EOT value is reached is defined as the time at which the increased rate in EOT is smaller than $0.1 \mathrm{~nm} / \mathrm{s}$ for 10 consecutive measured spectra (this is taken over a 100-second period). Such an instance is indicated in the graphs in Figure 5 a-e with a vertical dashed line. The estimated times to reach a stable EOT are: $1465 \mathrm{~s}$ for $50 \mu \mathrm{g} / \mathrm{mL}, 1009 \mathrm{~s}$ for $5 \mu \mathrm{g} / \mathrm{mL}, 792 \mathrm{~s}$ for $3 \mu \mathrm{g} / \mathrm{mL}, 444 \mathrm{~s}$ for $1 \mu \mathrm{g} / \mathrm{mL}$, and $192 \mathrm{~s}$ for $0,1 \mu \mathrm{g} / \mathrm{ml}$. Figure $5 \mathrm{f}$ plots these times as a function of the concentration. The graph shows clearly the existence of two different behaviors in the streptavidin binding process: a one-stage for low concentrations and a two-stage for high concentrations. It was also observed that at the very low concentration $(0.5 \mu \mathrm{g} / \mathrm{mL})$, a clear stable EOT signal was not obtained. 

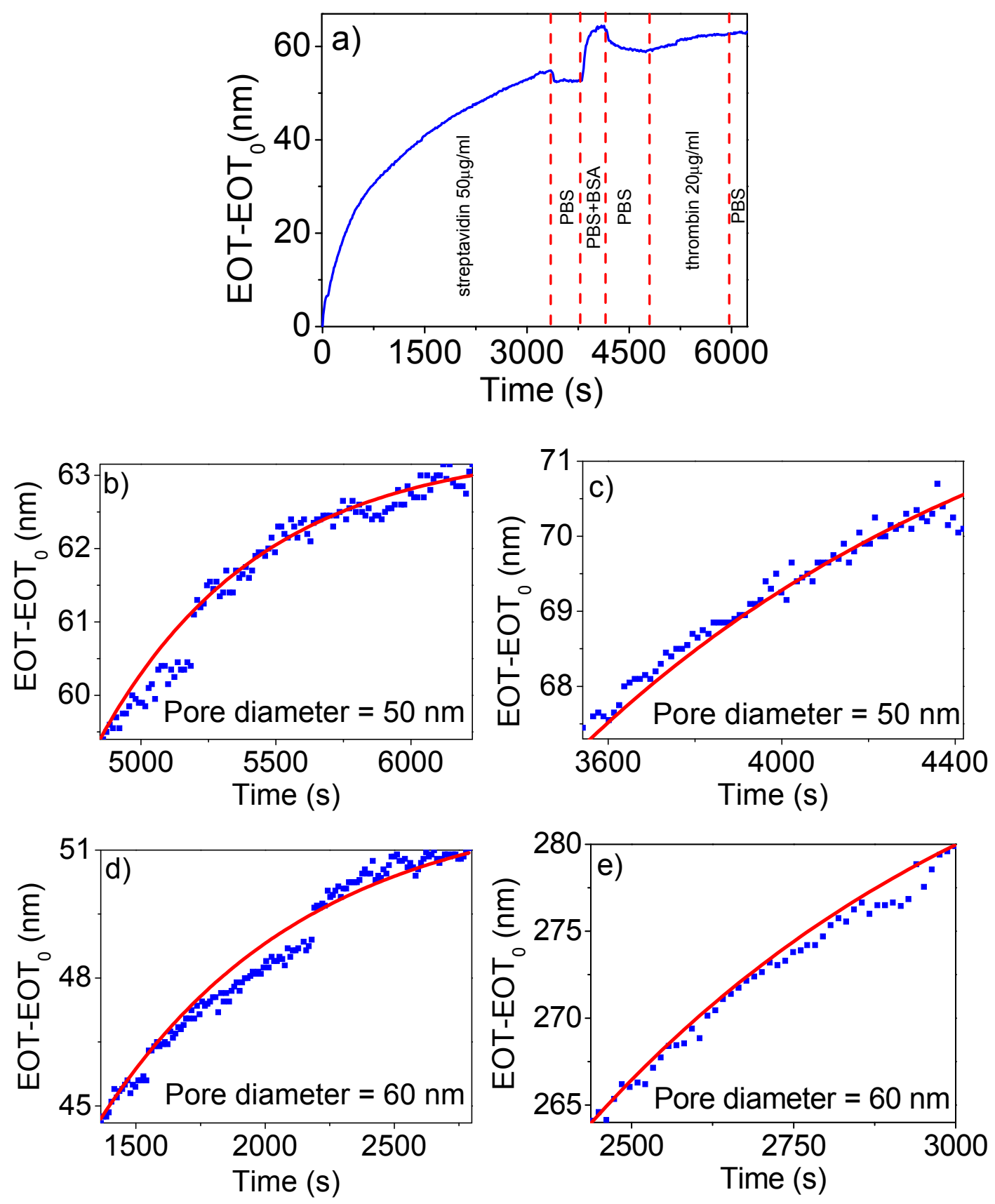

Figure 4. (a) Example of the registered change in EOT as a function of time for one of the performed biotinylated thrombin attachment experiments. (b,c) A close-up corresponding to the biotinylated thrombin step for two experiments corresponding to NAA with $50 \mathrm{~nm}$ pore diameter. (d,e) A close-up for the same step for two experiments corresponding to NAA with $60 \mathrm{~nm}$ pore diameter.

These two different ranges in the EOT changes with streptavidin concentration indicate that at high concentrations there are two different processes in the streptavidin attachment to the NAA pore walls. In the first stage, the activated carboxyl group of streptavidin $(-\mathrm{COOH})$ is bounded to the amino group of the APTES $\left(-\mathrm{NH}_{2}\right)$. Then, if the concentration of streptavidin is high, a second process occurs consisting of streptavidin-streptavidin aggregation as the activated carboxyl group of one streptavidin can bind with the amino group of another streptavidin. 

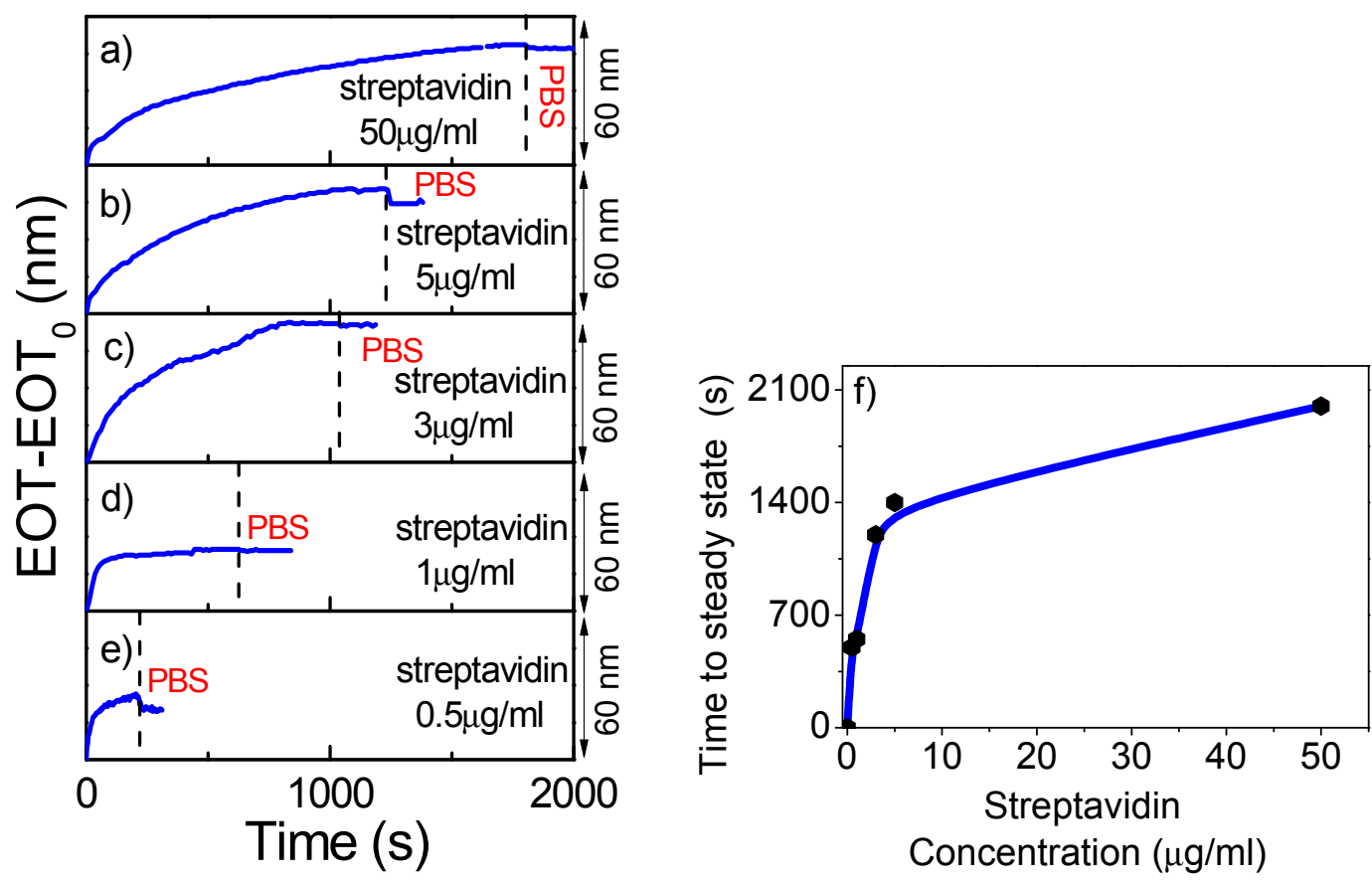

Figure 5. Variation of EOT against time for the streptavidin attachment step for different streptavidin concentrations, indicated in the plots. (a) $50 \mu \mathrm{g} / \mathrm{mL}$, (b) $5 \mu \mathrm{g} / \mathrm{mL}$, (c) $3 \mu \mathrm{g} / \mathrm{mL}$, (d) $1 \mu \mathrm{g} / \mathrm{mL}$, and (e) $0.5 \mu \mathrm{g} / \mathrm{mL}$. (f) Time to reach the steady-state against streptavidin concentration.

\subsection{Influence of the Biotinylated Thrombin Concentration}

To quantify the capabilities of the RIfS technique to detect the binding event of biotinylated molecules to NAA pore surfaces covered with streptavidin, different binding experiments were conducted for increasing biotinylated thrombin concentrations. The results of such experiments are shown in Figure 6. On the basis of the previous results, these experiments were carried for a fixed concentration of streptavidin at $1 \mu \mathrm{g} / \mathrm{mL}$ and for a $60 \mathrm{~nm}$ pore diameter. Figure 6a shows an example of the entire experiment: first we flowed PBS until a steady baseline EOT value was achieved. At $\mathrm{t}=0 \mathrm{~s}$, streptavidin $(1 \mu \mathrm{g} / \mathrm{mL})$ was introduced until a stable EOT was reached, at which point PBS was flowed to remove any unbound molecules. Next, the BSA solution is flowed to passivate the surface, followed by a subsequent PBS flow again to remove the non-bound BSA. The final step was the flow of the biotinylated thrombin solution at $20 \mu \mathrm{g} / \mathrm{mL}$ followed by a final PBS flow in order to wash all the non-binding molecules.

The introduction of streptavidin resulted in a rapid increase in the EOT signal, which became stable after $927 \mathrm{~s}$ in a single stage, providing a monolayer of streptavidin on the NAA pore surface. The washing with PBS produced a very small decrease in EOT consistent with the removal of any unbound molecules. The introduction of the BSA solution resulted in an increase of EOT corresponding to the electrostatic binding of the BSA to the NAA pore surface not previously covered with streptavidin. Subsequently, a decrease with the PBS-T flow was observed, down to an EOT above the value after the streptavidin step. This confirmed the effect of the passivation. Finally, when biotinylated thrombin was flowed, another increase in EOT was observed and a stable EOT value was reached after $1213 \mathrm{~s}$. The level of EOT remained the same after the final wash step with PBS.

Figure $6 \mathrm{~b}$ shows a close-up of the change in EOT corresponding to the biotinylated thrombin binding step for the experiment in Figure 6a. The graph shows that a clear increase in EOT can be observed until a stable EOT value is reached. For all the conducted experiments, the EOT level after the final PBS washing step is over to the EOT before the biotinylated thrombin addiction (Figure S3 supplementary material). The change in EOT in this last step after the PBS for this thrombin concentration leads to an $\triangle \mathrm{EOT}$ of $2.4 \mathrm{~nm}$. 
Figure 6c shows a plot of the $\triangle \mathrm{EOT}$ for the biotinylated thrombin concentration. Experiments were performed for the 10,20,50, and $100 \mu \mathrm{g} / \mathrm{mL}$ concentrations in triplicates for each concentration. The reported value corresponds to the average of the three replicas, while error bars correspond to the maximum and minimum measured $\triangle \mathrm{EOT}$. The blue lines connecting the experimentally measured points are included as a guide for the eye. The average $\Delta \mathrm{EOT}$ for each concentration are: $0.16 \mathrm{~nm}$ for of $10 \mu \mathrm{g} / \mathrm{mL}, 2 \mathrm{~nm}$ for $20 \mu \mathrm{g} / \mathrm{mL}$, and $7.5 \mathrm{~nm}$ for $50 \mu \mathrm{g} / \mathrm{mL}$, and with $10.6 \mathrm{~nm}$ for $100 \mu \mathrm{g} / \mathrm{mL}$. The graph indicates that thrombin can be clearly detected for concentrations above $10 \mu \mathrm{g} / \mathrm{mL}$ and that EOT response begins to saturate above $100 \mu \mathrm{g} / \mathrm{mL}$.
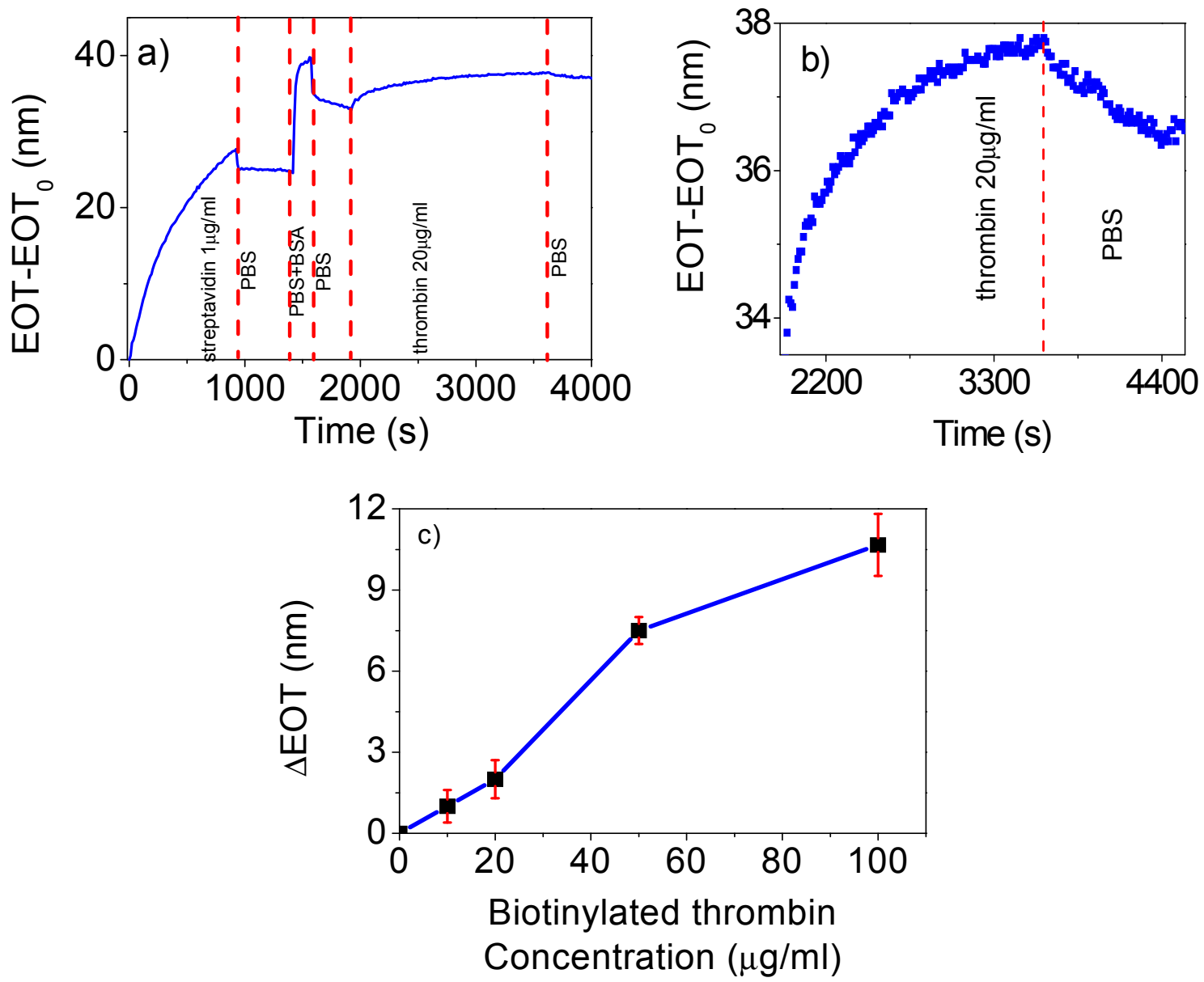

Figure 6. (a) Example of EOT variation with time for a biotinylated thrombin attachment experiment intended to evaluate the sensitivity of the NAA platform, corresponding to the concentrations specified on the graph. (b) A close-up of the EOT variation with time for one of the experiments conducted at a biotinylated thrombin concentration of $20 \mu \mathrm{g} / \mathrm{mL}$. (c) Total change of EOT in the biotinylated thrombin attachment step (EOT) against biotinylated thrombin concentration.

\section{Conclusions}

In this study, we demonstrate the ability of nanoporous anodic alumina-based reflection interferometric spectroscopy in the flow cell to monitor in real-time the attachment of thrombin through the streptavidin-biotin system. The results introduced in this work are proof that the streptavidin-biotin complex in NAA is a suitable platform towards RIfS-based biosensors.

We evaluated the influence of pore size diameter of NAA in the EOT response and estimated that the best value is around $60 \mathrm{~nm}$. Smaller pores can hinder the binding processes due to the reduced amount of space, while bigger pores are not achievable by the NAA preparation procedures. 
We assess the optimal concentration of streptavidin to obtain the best attachment of biotinylated thrombin. It was observed that, at concentrations above $1 \mu \mathrm{g} / \mathrm{mL}$, aggregation between streptavidin molecules was produced. On the other hand, concentrations below $1 \mu \mathrm{g} / \mathrm{mL}$ of streptavidin were not sufficient to produce complete coverage of the inner pore surface and led to noisy values in the EOT signal. These results show that the optimal concentration of streptavidin is $1 \mu \mathrm{g} / \mathrm{mL}$.

We monitored in real-time all the binding events from the silanized NAA from biotinylated thrombin attachment with special focus in the biotinylated thrombin binding event. This system can detect different concentrations of biotinylated thrombin. We prove that we can quantify biotinylated molecules at concentrations above $10 \mu \mathrm{g} / \mathrm{mL}$. The results in this work pave the way to apply NAA as an optical biosensor suitable for several kinds of biomolecules.

Supplementary Materials: The following are available online at http:/ /www.mdpi.com/2079-4991/9/3/478/s1. Figure S1: SEM images of NAA, Figure S2: Registered change in EOT as a function of time in entire experiments for different pore diameter, Figure S3: Best replicates of all the experiments for different concentrations of biotinylated thrombin.

Author Contributions: L.P. carried out the experiments. L.F.M. and J.F.-B. conceived and designed the experiments and supervised the study. All authors analyzed the data, contributed to scientific discussion, and wrote the manuscript.

Funding: This work was supported by the Spanish Ministry of Economy and Competitiveness under grant number TEC2015-71324-R (MINECO/FEDER), the Catalan Government AGAUR 2017-SGR-1527, and the ICREA under the 2014-ICREA Academia Awards.

Acknowledgments: The authors are grateful to Francisco Bertó, Pilar Formentín, José Guadalupe Sánchez, and to Pilar Montero Rama for help with manuscript preparation and for useful discussion and valuable comments.

Conflicts of Interest: The authors declare no conflict of interest.

\section{References}

1. Harris, M.D.; Tombelli, S.; Marazza, G.; Turner, A.P.F. Affibodies as an alternative to antibodies in biosensors for cancer markers. In Biosensors for Medical Applications; Woodhead Publishing: Sawston, UK, 2012; pp. 217-232.

2. Veloso, A.J.; Cheng, X.R.; Kerman, K. Electrochemical biosensors for medical applications. In Biosensors for Medical Applications; Woodhead Publishing: Sawston, UK, 2012; pp. 3-40.

3. Patel, S.; Nanda, R.; Sahoo, S.; Mohapatra, E. Biosensors in Health Care: The Milestones Achieved in Their Development towards Lab-on-Chip-Analysis. Biochem. Res. Int. 2016, 2016, 3130469. [CrossRef]

4. Kodadek, T. Protein microarrays: Prospects and problems. Chem. Biol. 2001, 8, 105-115. [CrossRef]

5. Khansili, N.; Rattu, G.; Krishna, P.M. Label-free optical biosensors for food and biological sensor applications. Sens. Actuators B Chem. 2018, 265, 35-49. [CrossRef]

6. Jauset Rubio, M.; Svobodová, M.; Mairal, T.; O'Sullivan, C.K. Surface plasmon resonance imaging (SPRi) for analysis of DNA aptamer: $\beta$-conglutin interactions. Methods 2016, 97, 20-26. [CrossRef]

7. Miyazaki, C.M.; Shimizu, F.M. Surface Plasmon Resonance (SPR) for Sensors and Biosensors. In Nanocharacterization Techniques; William Andrew Publishing: Norwich, NY, USA, 2017; pp. 183-200.

8. Zhao, J.; Zhang, X.; Ranjit Yonzon, C.; Haes, A.J.; Van Duyne, R.P. Localized surface plasmon resonance biosensors. Nanomedicine 2006, 1, 219-228. [CrossRef] [PubMed]

9. Unser, S.; Bruzas, I.; He, J.; Sagle, L. Localized surface plasmon resonance biosensing: Current challenges and approaches. Sensors 2015, 15, 15684-15716. [CrossRef]

10. Ito, T.; Asai, N.; Matsuda, Y.; Shingubara, S.; Jinba, T.; Shimizu, T. Fabrication and characterization of nano porous lattice biosensor using anodic aluminum oxide substrate. Jpn. J. Appl. Phys. 2017, 56, 06GG02. [CrossRef]

11. Li, K.; Wang, S.; Wang, L.; Yu, H.; Jing, N.; Xue, R.; Wang, Z. Fast and Sensitive Ellipsometry-Based Biosensing. Sensors 2017, 18, 15. [CrossRef]

12. Moore, T.J.; Moody, A.S.; Payne, T.D.; Sarabia, G.M.; Daniel, A.R.; Sharma, B. In vitro and in vivo sers biosensing for disease diagnosis. Biosensors 2018, 8, 46. [CrossRef] [PubMed] 
13. Law, C.S.; Lim, S.Y.; Abell, A.D.; Voelcker, N.H.; Santos, A. Nanoporous Anodic Alumina Photonic Crystals for Optical Chemo- and Biosensing: Fundamentals, Advances, and Perspectives. Nanomaterials 2018, 8, 788. [CrossRef]

14. Mariani, S.; Strambini, L.M.; Barillaro, G. Femtomole Detection of Proteins Using a Label-Free Nanostructured Porous Silicon Interferometer for Perspective Ultrasensitive Biosensing. Anal. Chem. 2016, 88, 8502-8509. [CrossRef]

15. Asai, N.; Shimizu, T.; Shingubara, S.; Ito, T. Fabrication of highly sensitive QCM sensor using AAO nanoholes and its application in biosensing. Sens. Actuators B Chem. 2018, 276, 534-539. [CrossRef]

16. Macias, G.; Ferré-Borrull, J.; Pallarès, J.; Marsal, L.F. Effect of pore diameter in nanoporous anodic alumina optical biosensors. Analyst 2015, 140, 4848-4854. [CrossRef] [PubMed]

17. Alvarez, S.D.; Li, C.-P.; Chiang, C.E.; Schuller, I.K.; Sailor, M.J. A Label-Free Porous Alumina Interferometric Immunosensor. ACS Nano 2009, 3, 3301-3307. [CrossRef] [PubMed]

18. Chhasatia, R.; Sweetman, M.J.; Harding, F.J.; Waibel, M.; Kay, T.; Thomas, H.; Loudovaris, T.; Voelcker, N.H. Non-invasive, in vitro analysis of islet insulin production enabled by an optical porous silicon biosensor. Biosens. Bioelectron. 2017, 91, 515-522. [CrossRef] [PubMed]

19. Kumeria, T.; Kurkuri, M.D.; Diener, K.R.; Parkinson, L.; Losic, D. Label-free reflectometric interference microchip biosensor based on nanoporous alumina for detection of circulating tumour cells. Biosens. Bioelectron. 2012, 35, 167-173. [CrossRef]

20. Rajeev, G.; Prieto Simon, B.; Marsal, L.F.; Voelcker, N.H. Advances in Nanoporous Anodic Alumina-Based Biosensors to Detect Biomarkers of Clinical Significance: A Review. Adv. Healthc. Mater. 2018, 7, 1700904. [CrossRef] [PubMed]

21. Toccafondi, C.; Proietti Zaccaria, R.; Dante, S.; Salerno, M. Fabrication of Gold-Coated Ultra-Thin Anodic Porous Alumina Substrates for Augmented SERS. Materials 2016, 9, 403. [CrossRef]

22. Santos, A.; Vojkuvka, L.; Alba, M.; Balderrama, V.S.; Ferré-Borrull, J.; Pallarès, J.; Marsal, L.F. Understanding and morphology control of pore modulations in nanoporous anodic alumina by discontinuous anodization. Phys. Status Solidi 2012, 209, 2045-2048. [CrossRef]

23. Kumeria, T.; Santos, A.; Losic, D. Nanoporous anodic alumina platforms: Engineered surface chemistry and structure for optical sensing applications. Sensors 2014, 14, 11878-11918. [CrossRef]

24. Baranowska, M.; Slota, A.J.; Eravuchira, P.J.; Macias, G.; Xifré-Pérez, E.; Pallares, J.; Ferré-Borrull, J.; Marsal, L.F. Protein attachment to nanoporous anodic alumina for biotechnological applications: Influence of pore size, protein size and functionalization path. Colloids Surf. B Biointerfaces 2014, 122, 375-383. [CrossRef]

25. Wu, J.; Ling, L.; Xie, J.; Ma, G.; Wang, B. Surface modification of nanosilica with 3-mercaptopropyl trimethoxysilane: Experimental and theoretical study on the surface interaction. Chem. Phys. Lett. 2014, 591, 227-232. [CrossRef]

26. Rajeev, G.; Xifre-Perez, E.; Prieto Simon, B.; Cowin, A.J.; Marsal, L.F.; Voelcker, N.H. A label-free optical biosensor based on nanoporous anodic alumina for tumour necrosis factor-alpha detection in chronic wounds. Sens. Actuators B Chem. 2018, 257, 116-123. [CrossRef]

27. Popat, K.C.; Mor, G.; Grimes, C.A.; Desai, T.A. Surface Modification of Nanoporous Alumina Surfaces with Poly(ethylene glycol). Langmuir 2004, 20, 8035-8041. [CrossRef] [PubMed]

28. Ferré-Borrull, J.; Xifré-Pérez, E.; Pallarès, J.; Marsal, L.F. Optical Properties of Nanoporous Anodic Alumina and Derived Applications. In Nanoporous Alumina: Fabrication, Structure, Properties and Applications; Losic, D., Santos, A., Eds.; Springer International Publishing: Cham, Switzerland, 2015; pp. 185-217. ISBN 978-3-319-20334-8.

29. Acosta, L.K.; Bertó-Roselló, F.; Xifre-Perez, E.; Santos, A.; Ferré-Borrull, J.; Marsal, L.F. Stacked Nanoporous Anodic Alumina Gradient-Index Filters with Tunable Multispectral Photonic Stopbands as Sensing Platforms. ACS Appl. Mater. Interfaces 2019, 11, 3360-3371. [CrossRef] [PubMed]

30. Bayer, E.A.; Ben-Hur, H.; Hiller, Y.; Wilchek, M. Postsecretory modifications of streptavidin. Biochem. J. 1989, 259, 369-376. [CrossRef] [PubMed]

31. Chaiet, L.; Wolf, F.J. The properties of streptavidin, a biotin-binding protein produced by Streptomycetes. Arch. Biochem. Biophys. 1964, 106, 1-5. [CrossRef]

32. Kurzban, G.P.; Bayer, E.A.; Wilchek, M.; Horowitz, P.M. The quaternary structure of streptavidin in urea. J. Biol. Chem. 1991, 266, 14470-14477. 
33. González, M.; Argarañ, C.E.; Fidelio, G.D. Extremely high thermal stability of streptavidin and avidin upon biotin binding. Biomol. Eng. 1999, 16, 67-72. [CrossRef]

34. Eckstein, C.; Acosta, L.K.; Pol, L.; Xifré-Pérez, E.; Pallares, J.; Ferré-Borrull, J.; Marsal, L.F. Nanoporous Anodic Alumina Surface Modification by Electrostatic, Covalent, and Immune Complexation Binding Investigated by Capillary Filling. ACS Appl. Mater. Interfaces 2018, 10, 10571-10579. [CrossRef] [PubMed]

35. Wolberg, A.S. Thrombin generation and fibrin clot structure. Blood Rev. 2007, 21, 131-142. [CrossRef] [PubMed]

36. Wang, J.; Du, W.; Huang, X.; Hu, J.; Xia, W.; Jin, D.; Shu, Y.; Xu, Q.; Hu, X. A novel metronidazole electrochemical sensor based on surface imprinted vertically cross-linked two-dimensional Sn 3 O 4 nanoplates. Anal. Methods 2018, 10, 4985-4994. [CrossRef]

37. Bang, G.S.; Cho, S.; Kim, B.G. A novel electrochemical detection method for aptamer biosensors. Biosens. Bioelectron. 2005, 21, 863-870. [CrossRef] [PubMed]

38. Higuchi, A.; Siao, Y.D.; Yang, S.T.; Hsieh, P.V.; Fukushima, H.; Chang, Y.; Ruaan, R.C.; Chen, W.Y. Preparation of a DNA aptamer-Pt complex and its use in the colorimetric sensing of thrombin and anti-thrombin antibodies. Anal. Chem. 2008, 80, 6580-6586. [CrossRef]

39. Porta-i-Batalla, M.; Xifré-Pérez, E.; Eckstein, C.; Ferré-Borrull, J.; Marsal, L. 3D Nanoporous Anodic Alumina Structures for Sustained Drug Release. Nanomaterials 2017, 7, 227. [CrossRef]

40. Wang, W.; Chen, C.; Qian, M.X.; Zhao, X.S. Aptamer biosensor for protein detection based on guanine-quenching. Sens. Actuators B Chem. 2008, 129, 211-217. [CrossRef]

41. Masuda, H.; Fukuda, K. Ordered metal nanohole arrays made by a two-step replication of honeycomb structure of anodic alumina. Science 1995, 268, 8-10.

42. Santos, A.; Formentín, P.; Pallarès, J.; Ferré-Borrull, J.; Marsal, L.F. Structural engineering of nanoporous anodic alumina funnels with high aspect ratio. J. Electroanal. Chem. 2011, 655, 73-78. [CrossRef]

(c) 2019 by the authors. Licensee MDPI, Basel, Switzerland. This article is an open access article distributed under the terms and conditions of the Creative Commons Attribution (CC BY) license (http:/ / creativecommons.org/licenses/by/4.0/). 